\title{
Statement to the Second International Conference on Assistance to Refugees in Africa
}

\author{
by \\ J.S. Stanford \\ Head of The Canadian Delegation \\ Geneva, July 9, 1984
}

The Secretary-General placed this important meeting in the context of the many efforts being made within the UN system to help member states in Africa deal with the problems and challenges which face that continent at the present time. In his message to the conference, the Chairman of the Organization of African Unity (OAU) brought home to us the importance of refugee problems and the urgent need of a number of African countries. The High Commissioner for Refugees and the Administrator of the UN Development Program outlined for us the dimensions of the humanitarian and development requirements which we are addressing at this conference, and the role which their organizations can play in responding to these requirements, provided they have the active support and effective cooperation of all governments represented here.

Canada is fully aware of the challenges facing Africa at the present time. We recognize and accept that African countries wish to, and indeed must, play the major role in dealing with the acute refugee situations which exist in Africa. The Canadian government and the Canadian people stand ready to assist in the search for practical and durable solutions.

As we look at the African scene and the multitude of refugees that have flowed across national borders in recent years, we are conscious not only of the suffering of those directly concerned - especially women and children, but also of the sacrifices imposed on host countries. It is only fitting that we recognize and commend the generous hospitality extended by so many African govern- ments and peoples to the refugees who have found it necessary to flee across national frontiers. These people have generally been received and treated with the greatest kindness and generosity. We urge that the international instruments for the protection of refugees, of which the OAU convention is the most comprehensive, continue to be respected.

ICARA I addressed the need to provide urgent relief to a dramatically increasing number of refugees on the African continent. In keeping with its traditional practice, Canada responded to those needs. But it was clear even at ICARA I that durable solutions could not be achieved if we simply focused on humanitarian relief, which may by itself perpetuate the problem. It was clear that greater attention had to be given by the countries directly involved as well as by outside donors - to promoting the integration of refugees in the development process, preferably through repatriation, but where that is not possible, in local settlement in the country of asylum. It is a step in the right direction that 55 percent of the UNHCR's budget for Africa is now devoted to durable solutions.

There was also general acceptance at ICARA I that solutions to refugee problems do not depend solely on the development assistance or host country investment that may be provided to help refugees integrate in the communities in which they have been established. There must also be a genuine and determined effort by the governments concerned to find political solutions to conflicts which give rise to refugees or which prevent refugees from returning to their homes. The OAU and the UN both have disputes settlement instruments and procedures which should be drawn upon where they can contribute to a solution.

The preparations for ICARA II have deliberately underlined the importance of seeking solutions which will endure. They have also underlined that the international community as a whole \$hould assist those countries which seek durable solutions, which are actively trying to re-establish returning refugees or which are undertaking measures to integrate and resettle refugees in their pwn societies and economies. One ceniral theme which has emerged out of these preparations is the need to help refugees help themselves. The excellent work done by the steering committee, IJN technical team and officials of participating African countries has indeed laid the groundwork for a well focused dialogue on these issues at this conference.

In light of these preparations and discussions, we have reviewed the list of projects presented by the technical team iffter consultation with African governments. It is worth noting that this list reflects a concerted effort to integrate refugees into the development process, and to better utilize their labour for their own advantage and that of host couniries.

While we look to the countries directly involved to exert their best efforts to remove the social and political causes, which have led refugees to flee their homes, we readily acknowledge that poverty and underdevelopment are factors which have contributed to refugee situations in some instances and which

6 
have inhibited their solution in othersi. The challenge of ICARA II is to determine how the international communityr can work with the countries of Africa to integrate refugees in the developmen: process - to help host countries of: countries of return deal with the difficult refugee situations facing them. Such measures and such assistance will lighten the burden on the host country? and will strengthen the country's social and economic infrastructure.

The lack of adequate resources and infrastructure, which may in some case; have contributed to an exodus, or which could render integration impossible, can be addressed through appropriate development inputs. In examinings the ways to proceed with this assistance, Canada has been guided by the following basic principles:

- First, assistance measures can be useful only if they are consistent with the long-term development programmes of the country concerned. They must alsi) be the subject of a continuing commitment by the host government to ensure that recurrent costs can be covered.

- Second, there must be tangible evidence that both the refugees and local communities will benefit mutually from external assistance.

- Third, the assistance should offer concrete possibilities for the integration of refugees into the national development effort.

- Fourth, appropriate income generating activities must be developed if they are not already in place. Employment in economically productive activities is the most important motor for integration and development.

ICARA II offers the opportunity to build on existing bilateral, multilater al and nongovernmental assistance in various ways. First, the conference w.ll sensitize world opinion to the needs of refugees in development as well as in relief. Secondly, it will further the process of examining the best ways in which humanitarian and development acti $v$ ities can be pursued together, in order : : achieve lasting solutions for refugees while providing the assistance needed by host governments to maintain their development efforts. Thirdly, it will give encouragement to those who are already involved in contributing to this effort.

In preparing for ICARA II, Canada has consulted with various Canadian nongovernmental organizations. While they have expressed their intention to continue to support refugees and displaced people in Africa, they rightly stressed that this is an activity in which they have been engaged for some time. The NGOs and International Agencies play a very significant role for which they should be warmly thanked.

A world should be said at this point about more immediate assistance for refugees. Recognizing the need for additonal humanitarian assistance, Canada wishes to reiterate its commitment to supporting the UNHCR's programme in Africa this year, at a level at least equal to that of the previous year. The UNHCR and its implementing partners can continue to rely on Canada for its sustained efforts, particularly in the pursuit of durable solutions. On behalf of the government of Canada I wish to take this opportunity to thank the High Commissioner for Refugees, his personnel and all the office's implementing partners for their dedication and perseverance in pursuing durable solutions.

I would now like to turn to Canada's response to the needs for continuing and additional assistance to refugees as set out in Resolution 37/197. With respect to projects submitted under paragraph $5(B)$ of this Resolution, my delegation is pleased to indicate an interest in funding five additonal projects in Zaire in the fields of agriculture, health, nonformal training for women, cooperatives and education. These projects will amount to \$US 1.2 million.

As I mentioned earlier, Mr. President, Canada attaches a great deal of importance to integrating refugees in the national development process. We fully support the rationale that underlies the submissions presented under paragraph $5(C)$ of the Resolution. Indeed, it is evident that infrastructural improvements are necessary to give refugee integration a chance of success. These improvements represent a large cost for the host country to sustain on its own. We believe that the international community has a role to play in helping to share the burden with host countries. Canada accepts this obligation, particularly in those countries where we have an established bilateral development assistance relationship.

After carefully examining the list of $5(\mathrm{C})$ projects in the context of our bilateral assistance programmes, we have identified ten projects, worth \$US 10.54 million, which we are interested in discussing with government officials in Zambia, Tanzania, Ethiopia, Botswana, Sudan and Zaire. These projects are in sectors such as agriculture, fisheries, health service, cooperatives and water supply. This does not, of course, preclude discussion of other refugeerelated projects during the course of normal bilateral consultations.

In the months following this conference, we will begin bilateral discussion to further define the projects we have identified and to address any problems which may arise, such as potential duplication of interest by the donor community. A measure of flexibility will be required to sort out difficulties and to come to final agreements on the implementation of ICARA II projects. We believe that arrangements can best be reached to the satisfaction of all interested parties through direct consultations among them. A continued dialogue between interested governments, rather than the creation of temporary bodies, will lead to the timely and effective implementation of the projects.

It is Canada's firm belief that the problems addressed at ICARA II are soluble. This conference can succeed in creating a spirit of cooperation that will bear fruit over the next few years. Through ICARA II we are beginning an essential dialogue between those responsible for development and those providing more traditional refugee assistance. If we resolve that this dialogue, involving as it does both donor countries and the countries of asylum of Africa, will lead to concrete action, then the "time for solutions" is indeed at hand. 
tivatable land are not available. Therefore, the only alternative to permanent dependence on relief is to create income-generating opportunities on a large scale.

Several things flow from this conclusion. First, creating income-generating opportunities is another way of saying development projects. In other words, under current conditions in the lowincome countries, durable solutions can only be achieved through developmentoriented assistance from the outset. Secondly, "for social, psychological and political reasons, this can hardly be done for refugees alone" (UNHCR, 1983c). Both the refugees and the local population must be included. This means that the system has moved from humanitarian assistance to refugees, to creating income-generating opportunities for refugees, to developmentoriented assistance, from the outset, "for the whole area where the refugees live".

This large leap leads to the other central focus of the refugees and development discussions, the need for new institutional arrangements to carry forth such double-target projects. "No single international organization has the mandate, the expertise and the funds required" (UNHCR, 1983c).

Finally there is the issue of "additionality". This is a major issue that has appeared in both set of discussions and is closely connected to the question of infrastructural burden-sharing. Lowincome host countries want refugee assistance of all types, but particularly development-oriented assistance, to be over and above, additional to, the normal development assistance they would receive if there were no refugee situation. Donor governments, on the other hand, point to limited availability of funds and the impossibility of expanding the assistance purse. While the donors recognize that it is not equitable for the asylum countries to have to share their resources with refugees, the donors indicate that refugees incorporated within development projects should be "potential contributors" to the development of an area. "It is reasonable, therefore, for host countries to accept that a share of the (development) assistance... should also apply to the refugee areas" (UNHCR, 1984a). In other words, partial rather than full additionality.
Finally, some brief comments on the seven key issues and principles that have emerged from this process.

1. Equitable Burden-Sharing. For lowincome countries the presence of refugees places a burden on many sectors of their economy and society. The ICARA II Declaration "recognizes that the condition of refugees is a global responsibility... and emphasizes the need for equitable burden-sharing" and that:

As a result of the adverse impact on the national economies of the. . .least developed countries, there is need to provide these countries with the required assistance to strengthen their social and economic infrastructure.

2. Spontaneously Settled Refugees mixed among the local population are a main reason why an expanded concept of burden-sharing was developed and also are central to requests for new forms of refugee assistance. Traditional UNHCR assistance designed essentially to benefit refugees has great difficulties reaching refugees who are not in discrete units. The burden thus falls on the host country.

3. Aid to Both Refugees and Locals. As a response to the difficulties of aiding spontaneously settled refugees the principle has emerged that:

In low-income areas, the needs of the local people should also be taken into account, in such areas developmental initiatives may therefore be needed which would permit both refugees and local people to engage in economically productive activities to ensure them a decent livelihood (UNHCR, 1984d).

The need for development initiatives and the inclusion of the local people moves this aid beyond UNHCR's competence and thus will be a difficult principle to implement.

4. Additionality. With regard to the question of total or partial additionality no agreement on principle has been achieved, only a statement that can be read either way: "such projects should normally be additional to, and not at the expense of, the country's other development programs (UNHCR, 1984d).

5. Development-Oriented Assistance. The ICARA II Declaration states that:

For solutions to last, assistance to refugees and returnees must aid at their participation, productivity and durable self-reliance; it should be development-oriented as soon as possible.

This principle represents an important and fundamental reorientation of traditional refugee assistance. It represents an attempt to view refugee assistance as a comprehensive integrated solutionoriented process rather than as a series of ad hoc reactions to problems.

6. Durable Solutions. "Refugee problems demand durable solutions" (UNHCR, 1984d) but in fact no such demand is made and this principle is greatly weakened by the political realities that give many refugees only temporary settlement at best. In some ways the heart of the new approach is "temporary measures pending a durable solution" and the need to make the best of a long-term temporary situation by promoting refugee productivity and selfreliance while waiting for solutions.

7. New Institutional Arrangements will be needed to put these new principles into action. A major achievement of the process of discussion thus far has been the alerting of the development community, in the hosts, donors and the UN system, to these issues and problems. In particular the United $\mathrm{Na}$ tions Development Program has stated that it "stands ready" to continue active participation, and the World Bank, the International Labour Office and the World Food Program have also become more active in this field.

The refugee assistance system has for the most part successfully cleared a crucial hurdle in its efforts to alter the ways in which refugee assistance is provided in developing countries. The results thus far are impressive and are an indication of the responsiveness and adaptability of the refugee assistance system when it is faced with fundamental changes in conditions. The 35 th session of the Executive Committee of the High Commissioner's Program effectively closed the first phase of response by approving a set of "Principles for Action in Developing Countries" that have been drawn from the ICARA meetings and from UNHCR's meetings on Refugee Aid and Development. The second phase will involve putting these principles into operation in Africa, as a follow-up to ICARA II, and globally. 